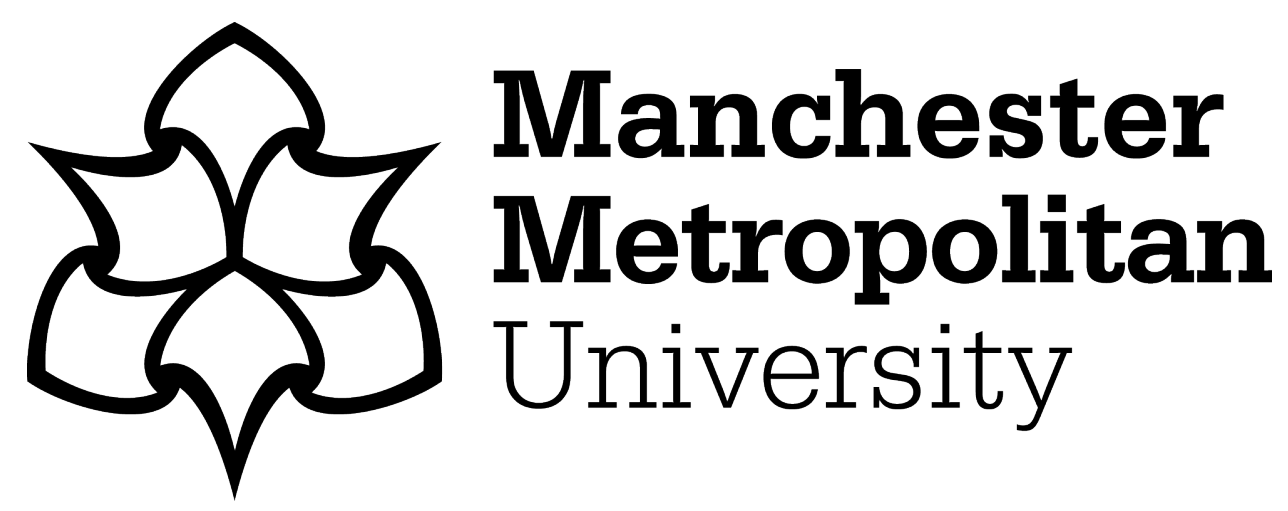

St Clair, Rebecca ORCID logoORCID: https://orcid.org/0000-0002-40801289, Hardman, Michael, Armitage, Richard and Sherriff, Graeme (2020) Urban Agriculture in shared spaces: the difficulties with collaboration in an age of austerity. Urban Studies, 57 (2). pp. 350-365. ISSN 0042-0980

Downloaded from: https://e-space.mmu.ac.uk/622420/

Version: Accepted Version

Publisher: SAGE Publications

DOI: https://doi.org/10.1177/0042098019832486

Please cite the published version 


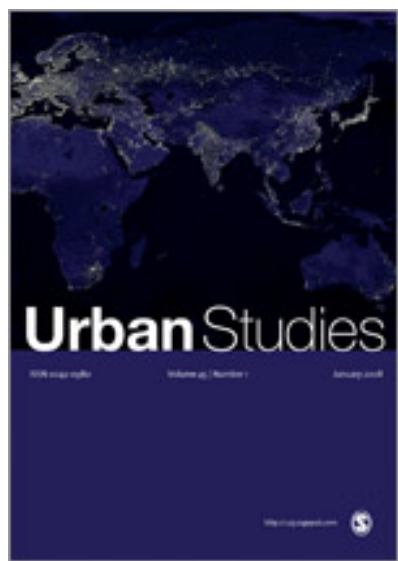

\section{Urban Agriculture in shared spaces: The difficulties with collaboration in an age of austerity}

\begin{tabular}{|c|c|}
\hline Journal: & Urban Studies \\
\hline Manuscript ID & CUS-914-18-09.R1 \\
\hline Manuscript Type: & Article \\
\hline $\begin{array}{l}<\text { b }>\text { Discipline: Please select a } \\
\text { keyword from the following } \\
\text { list that best describes the } \\
\text { discipline used in your paper.: }\end{array}$ & Geography \\
\hline $\begin{array}{r}\text { World Region: Please select } \\
\text { the region(s) that best reflect } \\
\text { the focus of your paper. } \\
\text { Names of individual countries, } \\
\text { cities \& economic groupings } \\
\text { should appear in the title } \\
\text { where appropriate.: }\end{array}$ & Western Europe \\
\hline $\begin{array}{r}\text { Major Topic: Please identify } \\
\text { up to } 5 \text { topics that best } \\
\text { identify the subject of your } \\
\text { article.: }\end{array}$ & $\begin{array}{l}\text { Community, Environment/Sustainability, Local Government, Land Use, } \\
\text { Social Justice }\end{array}$ \\
\hline $\begin{array}{r}\text { You may add up to } 2 \text { further } \\
\text { relevant keywords of your } \\
\text { choosing below: }\end{array}$ & Urban Agriculture, Neoliberalism \\
\hline
\end{tabular}

\section{SCHOLARONE" Manuscripts}




\title{
Urban Agriculture in shared spaces: The difficulties with collaboration in an age of austerity
}

\begin{abstract}
The expanding critical literature on Urban Agriculture (UA) makes links between the withdrawal of state services and the institutionalisation of volunteering, while observing that challenging funding landscapes can foster competitive environments between third sector organisations. Where these organisations are forced to compete for survival at the expense of collaboration, their ability to collectively upscale and expand beneficial activities can be compromised. This paper focuses on a lottery-funded UA project and draws predominantly on observations and interviews held with project staff and growing group volunteers. Research conducted in Wythenshawe, Manchester (UK), highlights difficulties experienced by organisations attempting to function in an environment disfigured by depletion, illustrating conflicts that can arise between community groups and charitable organisations competing for space and resources. Inter-organisational dynamics are considered at two scales; at the grassroots level between growing groups, and at a structural level between project partners. In a landscape scarred by local authority cutbacks and restructures, a dearth of funding opportunities and increasingly precarious employment, external initiatives can be met with suspicion or hostility, particularly when viewed as superfluous interventions. The resulting "siege mentality" reflects the need for organisational self-preservation but perhaps paradoxically results in groups with similar goals and complementary ideologies working against each other rather than in cooperation.
\end{abstract}

\section{Keywords}

Urban Agriculture; critical geography; neoliberalism; community growing; urban farming

\section{Introduction}

As the prevalence of both grassroots and formal or "institution-led" Urban Agriculture (UA) initiatives increases across the UK, critical scholars have called for a move away from the advocacy narrative traditionally associated with UA research and for a greater consideration of the more contentious implications of growing food in cities (Tornaghi, 2014). Accordingly, 
research has sought to place UA activities within the context of social and environmental justice and to critique both its relationship with and its influence on the existence, development and ratification of a neoliberal hegemony. This paper is based on ethnographic research conducted with Real Food Wythenshawe (RFW), an institution-led UA project in Manchester (UK), over a two-year period. Here, we aim to move the narrative of UA forward, by exposing restrictions felt by UA practitioners in their ability to work as a collective in a challenging funding landscape. We suggest that while UA has potential to provide beneficial impacts, in some cases this is impaired by an inability to combine and augment efforts. Consequently, we call for a rejuvenated consideration of how shared environments that promote cooperation may be developed to allow UA projects to become more than the sum of their parts.

The body of this paper is divided into the following sections: the first begins by introducing critical conceptualisations of UA in order to establish the theoretical narrative for the paper. This is followed by a description of RFW, the UA project that is the subject of the research and a description of the research methods used. The presentation and discussion of findings are divided into two parts. First, a description of the place of research, Wythenshawe Farm, provides background and context, and dynamics between growing groups at a grassroots level are explored. This is followed by a description of the project's ability to establish and maintain partnerships, continuing the theme of collaboration, but moving away from the growing activities and towards the structural level of the project and its stakeholders. These sections are followed by concluding remarks and suggestions for future research. Throughout the paper, we contend that while UA projects can often be seen to provide positive impacts on participants and surrounding communities (e.g. increased access to food (McClintock \& Simpson, 2018), health benefits (Alaimo, Beavers, Crawford, Snyder, \& Litt, 2016; Bellows, Brown, \& Smit, 2003), community cohesion (Armstrong, 2000) and skills acquisition (Okvat \& Zautra, 2011)), their ability to collectively upscale is currently compromised by a competitive funding environment that is exacerbated by successive years of austerity policies in the UK.

\section{Critical conceptualisations of UA}

UA can be broadly described as the practice of "food cultivation and animal husbandry on urban and peri-urban land" (Tornaghi, 2014, p. 551). While private and allotment gardening in towns and cities is a familiar phenomenon to many in the UK, the commercial cultivation of crops in urban areas remains a relatively novel concept (Hardman \& Larkham, 2014). Community UA schemes are becoming increasingly popular in the UK, and demand for urban land for food 
production is rising (Church, Mitchell, Ravenscroft, \& Stapleton, 2015). The recent surge in the popularity of UA activities has led to a more critical assessment of the impacts and implications of the practice, largely from a social and an environmental justice perspective.

While proponents cite the benefits and potential of UA (Mougeot, 2010; Smit \& Nasr, 1992), critical scholars also acknowledge its tendency to further the entrenchment of neoliberal structures by inadvertently providing alternatives to services traditionally offered by the state (McClintock, 2014; Pudup, 2008; Tornaghi, 2014). UA activities such as community gardening are thought to hold the capacity to both critique and provide alternatives to "traditional stateprovided open spaces" (Rosol, 2012, p. 240), while inadvertently entrenching neoliberalism or exacerbating forms of social injustice and exclusion by softening the blow of financial crises and by default supporting the retraction of state welfare provision (McClintock, 2014; Pudup, 2008). There is therefore a need to critically analyse "processes of neoliberalisation in the practice of urban development" and to explore the development of "soft [outsourcing] strategies" such as the involvement of NGOs and volunteers in the process of governance (Rosol, 2012, p. 239).

The expanding literature base in the North American context of UA suggests that community growing projects are often politically motivated, developing in response to or in conjunction with a variety of stimuli. These include natural disasters, the retraction of state welfare provisions, civil rights movements, a rejection of the corporate nature of our food system, and the emergence of food deserts following industrial decline and urban decay (see, for example: Baker, 2004; Colasanti, Hamm, \& Litjens, 2012; Draus, Roddy, \& McDuffie, 2014; Ferris, Norman, \& Sempik, 2001; Kato, Passidomo, \& Harvey, 2014)). Milbourne (2012) and more recently St. Clair, Hardman, Armitage, and Sherriff (2017) have questioned the applicability of this narrative in the UK, finding little evidence that community growing group members are explicitly driven to act in protest to the systematic diminishment of state intervention or for political change. From this perspective, the emergence of neglected public spaces can be viewed as a double-edged sword that while symptomatic of a shrinking state, also gives residents the opportunity to "wrestle back control of local space" and to engage in the development of a more democratic community, forming new spaces of social justice (Milbourne, 2012, p. 955). In this regard, the absence of state intervention concerning the maintenance of public spaces may represent an opportunity to generate engaged, inclusive communities from the grassroots. 
In an attempt to move beyond the somewhat dichotomous framing of UA as either an accomplice in the neoliberal project or as an instrument of revolt, Crossan, Cumbers, McMaster, and Shaw (2016, p. 5) have applied the term "Do It Yourself (DIY) Citizenship" to the actions of community gardeners in a Glasgow-based study. They describe the term as:
A form of citizenship that is generative of collaborative social relations and new urban places, while also being disruptive, in unsettling neoliberalism's penchant for atomized individuals and reversing its frequently wasteful spatial practices.

This portrayal of urban growing avoids labelling the activity as necessarily radical or as a mechanism by which participants unwittingly entrench neoliberal structures and give a tacit approval of the dominant political hegemony. Implicit in this description is also an acceptance that while the actions of UA practitioners may not exclusively be politically driven, the outcomes of such practices may resemble unintentional subversion, generating new practices that lead to incremental political reorganisation from the ground-up (St. Clair et al., 2017). Moreover, DIY citizenship perhaps provides a window through which scholars can begin to view UA activities in a manner that theoretically disentangles the practice from these contradictions, hitherto detailed by McClintock (2014).

While academic attention has been paid to health, horticulture and allotments, literature on community food initiatives has so far largely failed to critically engage with the question of their ability to tackle food injustices and as yet, it is still unclear who the overall beneficiaries of urban community food growing projects really are (Franklin, Kovách, \& Csurgó, 2016; Horst, McClintock, \& Hoey, 2017). Bell and Cerulli (2012) question the ability of community UA projects to contribute to social justice and sustainability and are critical of the practice's overall potential impact on urban food systems, while Tornaghi (2017) has more recently questioned the extent to which urban growing results in the production and harvesting of healthy food for the purpose of consumption. Indeed, while food-growing initiatives in the UK often seek to bring people together, reduce social isolation and to teach and inspire people to cultivate vegetables, in some cases the focus on preparation, planting and tending stops short of harvesting, sharing and consuming. This somewhat troubling dislocation between the production and consumption of food is surprising given UA's frequent employment as a tool to bridge the perceptual gap between farm and fork for urban dwellers. 
In an attempt to strengthen the association between community food initiatives and justice, Kneafsey, Owen, Bos, Broughton, and Lennartsson (2017, p. 2) call for narratives to be situated in a "social, environmental or food justice framework". They claim that in efforts to retain political neutrality, charities avoid "the politicised language of "food justice"" in the knowledge that they operate within challenging funding environments where like-minded organisations can be forced to compete for survival (Kneafsey et al., 2017, p. 11). Moreover, while describing the community gardens of Glasgow as a collective movement, Cumbers, Shaw, Crossan, and McMaster (2018) acknowledge that financial tensions brought about by local authority budget cuts and loss of employment can place additional strain on third sector organisations and lead to the development of competitive environments.

The inter-organisational inclination towards competition somehow jars with the increasingly accepted view that UA activities such as community growing groups and allotments can provide fertile environments for a "shared politics of space" (Corcoran \& Kettle, 2015, p. 1215). This suggests that while UA activities may have the power to "create and sustain civil interfaces - dismantling barriers, exchanging knowledge, challenging stereotypes [and] generating empathy" (Corcoran \& Kettle, 2015, p. 1215), the existing overarching political environment hinders the development, growth and integration of these supportive niches, instead compelling them to exist predominantly as isolated endeavours.

Influenced by Holloway (2010), Tornaghi (2017, p. 783) describes the piecemeal nature of UA initiatives as "cracks", chipping away at the injustices of the capitalist system and calls for "a confluence of the cracks" whereby actions promoting food justice can multiply, bind together and expand. To analyse the potential for this gathering of cracks, we must also understand how (and if) groups are able function as a collective within the existing neoliberal framework. This paper aims to shed light on how community growing groups in a shared space can experience difficulties fostering a supportive environment and calls for a renewed consideration of the ways in which efforts of UA initiatives can be strengthened and encouraged to act collectively. Our research also highlights that once partnerships are established, their maintenance depends on continued and effective communication in addition to mutual benefit for each party. These issues are explored through a focus on an institution-led UA project in Wythenshawe, South Manchester, which is introduced and described in the following section. 
The Research Focus: Real Food Wythenshawe and Wythenshawe Farm

$\mathrm{RFW}^{1}$ is a UA project operated by staff based at the offices of the project's lead partner, a local social housing provider. The initiative was awarded $£ 1$ million by the Big Lottery in 2012 as part of the Communities Living Sustainably (CLS) funding stream, and commenced activities in early 2013 following the appointment of a project manager and three coordinators. The project has since been awarded additional funding to continue to deliver specific elements of their work, however the research forming the basis of this paper was conducted between 2015 and 2017 and concentrates on the initial period of funding and project implementation.

Wythenshawe experiences high levels of deprivation, particularly in relation to health and employment and the district contains very few retail outlets selling fresh, local food (Open Data Communities, 2015; St. Clair et al., 2017). RFW seeks to help residents to learn to grow and cook healthy food by focusing on three themes: growing, cooking and learning, encompassed within five flagship areas. One flagship specifically concerns growing activities at an urban farm in Wythenshawe, which acts as the case study for this research. Urban farming is a type of UA activity defined by the European Federation of City Farms as:

\begin{abstract}
Agricultural projects, where visitors of all ages and backgrounds can get in touch with animals, nature, their environment and each other. City farms offer training and information, a social and cultural meeting point, recreation, therapy or fulfilling day care activities... City farms are green spaces in the middle of a busy, fast and urbanised world.
\end{abstract}

(European Federation of City Farms, n.d. para. 1)

\begin{abstract}
Wythenshawe Farm is home to a variety of animals including sheep, goats, pigs, ducks, hens, horses and a herd of Hereford cattle. A large walled garden within the farm offers space for community groups to cultivate vegetables. The farm - which is situated within Wythenshawe Park, 109 hectares of open parkland owned and managed by the local authority - is open to the public free of charge.
\end{abstract}

RFW organises a weekly growing session at the farm and a number of other growing groups meet at the park independently of the RFW project, having done so since before the project began. During the time of research, produce grown at the farm by RFW was used in a number

\footnotetext{
${ }^{1}$ https://www.realfoodwythenshawe.com/
} 
of ways including for display at horticultural shows, or as ingredients in cookery demonstrations. Due to the somewhat sporadic nature of volunteer attendance, the uneven production of crops could not reliably supply the farm shop; however, produce was occasionally sold in the shop when available. Since RFW began in 2013, the project staff members have assisted with the redecoration of the farm shop and have helped to identify local suppliers for certain products. RFW also provided funding for one part-time employee for the shop on a temporary basis until 2017.

The site is of interest from a research perspective as although there is a growing body of literature on community gardening, there has been a lack of critical engagement specifically with urban farms as spaces of food production, community growing and knowledge exchange (Hardman, Chipungu, et al., 2018). As the site is based within a large area of land and has an associated commercial outlet, the farm may also have more scope to upscale operations than smaller UA sites such as community gardens, which often lack the capacity to expand their activities. Furthermore, as Franklin et al. (2016) observe, while there exists a burgeoning literature on the functionality of common land, the governance and use of publicly-owned spaces and their potential for community food growing has thus far been under examined.

\section{Methods}

The findings in this paper are based on observations and interviews conducted over a two-year period in Wythenshawe. The process of gaining access to the RFW project began with the identification of key actors and gatekeepers. Early observations were conducted in the offices of the local housing association where the RFW team was based, and through attending meetings and events. Researcher (corresponding author) participation at the urban farm growing sessions began with visits facilitated by the RFW growing coordinator, who acted as the group leader, organising sessions on a weekly basis. Once contact had been made with the study site, regular engagement allowed for rapport to be built with the group members and for a more in-depth understanding of the growing activities and group dynamics. Through continued attendance at RFW events and activities, a familiarity was established between the researcher and the project staff and participants.

Participant observation was used throughout the duration of the fieldwork to allow the researcher to integrate with and observe participants, adopting the role of "observer as participant" (Gold, 1958). This level of integration was deemed appropriate as it allowed for a 
comprehensive understanding of the group and their activities while ensuring that members of the group were aware of the researcher's role from the outset. Spradley $(2016$, p. 39) identifies three significant aspects of social situations as "place, actor, and activities", which can act as a guide when observing social phenomena. While accepting the assertion that the "researcher's tacit knowledge and expectations often play a major role in determining which observations are worthy of annotation" (Wolfinger, 2002, p. 85), the three factors highlighted by Spradley provide a helpful starting point for the focus of field notes. Accordingly, field notes were composed detailing information regarding the location of the fieldwork, the names of people present, the dates of the activities, the types of activities carried out and conversations that took place.

In-depth semi-structured interviews $(n=16)$ were held with the RFW project manager, coordinators, authors of the funding bid, and farm staff and volunteers, building upon initial and ongoing observations. Interviews were recorded using an audio recorder and transcribed by the corresponding author. Field notes were collected throughout the duration of the research, and were read and reflected upon continuously in order to inform interview questions and frame discussions. In this sense, the analysis was an ongoing process from the beginning of the data collection period and employed a constructivist-grounded theory approach. As per Charmaz's description of grounded theory coding, transcripts were analysed through a process of initial or open coding followed by the development of categories through intermediate or axial coding (Birks \& Mills, 2015; Charmaz, 2006). NVivo 11 was used to develop the thematic coding framework and the emerging themes form the basis of the paper. As per the conditions of consent, interviewee's names have been changed to retain anonymity. Interview data is drawn upon in the following two sections to illustrate the project's experience of working in collaboration with others, initially at a grassroots level, and subsequently at the partnership level.

UA in public spaces: Conflict at the expense of cooperation at the grassroots level

Wythenshawe Park is an example of a local authority-managed public space, where the quantity of paid staff members has been in decline for a number of years. This coincides with the recent trend of cuts by local authorities in England, whose spending powers were reduced in real terms by $27 \%$ between 2010/11 and 2015/16 (Hastings, Bailey, Bramley, Gannon, \& Watkins, 2015). In Manchester, the City Council (MCC) has made overall savings of $£ 357$ million since 2010/11, with a reduction of staff (full time equivalent) from 9,310 in 2010/11 to 
6,100 in 2017/18 (Hindle, 2018). As the RFW manager recalled, "In the 1980s, when [the park] was probably in its heyday, there was 24 gardeners at Wythenshawe Park and now there are none" (RFW project manager). The dwindling number of paid employees responsible for maintenance has left the park and farm heavily reliant on volunteers, a development recognised in MCC's 10-year action plan for parks, which emphasises the need for "effective resourcing for volunteers, Friends groups, community groups and third sector organisations" (MCC, 2017, p. 18). While MCC seeks to support volunteer groups who assist in the maintenance of parks, there is currently no policy that facilitates gardening on available or "meanwhile" spaces within parks (Cassidy, 2018).

During an interview, the farm assistant revealed that the farm employs just two full-time paid members of staff in addition to the part-time farm shop assistant employed by RFW. The farm also has approximately 50 registered volunteers, without whom it may struggle to carry out day-to-day operations. The unpaid workforce in the park also includes workers from government-organised work schemes such as Seetec, which aims to encourage the long-term unemployed back into work. As the farm assistant explained, Seetec volunteers work at the farm "five days a week and it gets them into the habit of getting up and getting ready and going to work, and going home again. It just gets them back into that routine" (Wythenshawe farm assistant). A regular sight at the park was a team of community payback recruits (a community sentencing scheme in the UK), who could be seen helping with planting, landscaping and general maintenance around the park.

Rosol (2012, p. 250) makes the important distinction between "voluntarism and workfare", with the former represented by citizens who occupy a position of privilege, having spare time to pursue hobbies and interests; and the latter functioning as an instrument of government, used to "control the unemployed and discipline the lower classes". This essentially professionalised volunteer workforce functions within a managerial and often competitive environment, which may in turn make collaboration and cooperation more difficult to foster among groups working towards similar goals (Fyfe \& Milligan, 2003; MacKinnon, 2000; Rosol, 2012). The teams of Community Payback and Seetec workers, who were frequently visible assisting with manual labour within Wythenshawe Park, signalled a shift towards the outsourcing of public service provision within a publicly managed space.

A dependence on voluntary labour (as distinct from workfare) is a feature of UA initiatives that has been the subject of recent attention from academics, particularly focusing on the potential 
implications this may have for social justice and the entrenchment of inequalities (Ghose \& Pettygrove, 2014; Rosol, 2012). This is, in part, due to the preconditions for volunteering, which tend to demand that individuals have the free time and resources to dedicate their efforts to a cause without payment, a privilege to which not all people have access. As Alkon and Agyeman (2011, p. 2) note, the people involved in local food activism are very often "white and middle class", making the sustainable food movement "something of a monoculture". The dominant representation of affluent individuals is particularly problematic when the associated activities are based in areas of high deprivation or are striving for societal change, as it affords a higher level of political agency to those who arguably need it less. Similarly, in a recent review of the literature on planning, UA and food justice, Horst et al. (2017) comment that UA initiatives tend to disproportionately benefit less deprived communities.

The capacity of volunteer-led community projects to fill gaps in provision has been the subject of debate for some years (Alexander, Nank, \& Stivers, 1999) and while the farm has a large number of registered volunteers, it is nevertheless subject to the sporadic nature of volunteer attendance. The farm assistant recognised that this is "the nature of volunteering, because people come in as and when... it's not top priority" (Wythenshawe farm assistant). This sentiment was echoed by one of the RFW volunteers, who felt that growing projects' characteristically heavy reliance on flexible and unregulated voluntary labour is impractical "[as] volunteers can be time limited" and may decide after attending once or twice that "they don't want to come again" (Amy, RFW volunteer). Amy felt that it was particularly unfair for retired volunteers to be expected to fill the labour gap created by a lack of paid opportunities and irregular volunteer attendance, adding, "I haven't retired and gone into this for that" (Amy, RFW volunteer). As Milligan (2000, p. 195) observes, "voluntary sector development... is often piecemeal and sporadic, owing as much to the availability of resources as it does to any planned action based on an identified need". This observation raises questions regarding the ability of UA schemes to sustain coordinated actions with the potential to alleviate food insecurity through the production of local, affordable food.

In Wythenshawe, budget cuts have also caused the local authority to fill gaps in service provision by expanding the roles of employees and combining interdepartmental labour. In 2011/12 the MCC Parks team joined with Libraries and Culture to form Community and Cultural Services until 2016 when Parks once again became a standalone service (Cassidy, 2018). During this period, the departmental merging meant that staff who previously felt secure 
in their employment were assigned roles for which they may have lacked the relevant experience or expertise. As Isabel, RFW's farm shop assistant, and an ex-council employee explained:

I worked in libraries for 38 years, and then four years ago, libraries and parks merged... Because they didn't have a lot of park staff to look after the parks, the library staff then became responsible for putting jobs on for repairs to the playgrounds and various things... but that's all changing now. So libraries and parks are now splitting again, so the library staff won't be responsible for that... There's only going to be one manager over three parks now.

(Isabel, farm shop assistant)

The precariousness of the situation appeared to create a fertile environment for suspicion and resentment between users of the space. Prior to the establishment of the RFW weekly growing sessions, Wythenshawe Park already hosted a number of growing groups in different areas of the park and farm run by various organisations and serving a range of needs. The RFW coordinators spoke of the difficulties they experienced in their attempts to share the space with other growing groups, with the project manager observing that staffing cuts made collaborative work particularly difficult to negotiate as "people just go into siege mentality". She suspected that the situation would not improve over the coming years, fearing that further cuts were yet to be made:

The staff that have been there [for a long time]... [are] probably on the third restructure where... they've had to be interviewed three times for their own jobs over the last four or five years, they've just become very cynical about everything.

(RFW project manager)

RFW's first growing coordinator, who left the project during its second year of funding, observed conflict between various actors at Wythenshawe Park early in the project, hypothesising that these tensions were frequently exacerbated by staff cuts and job changes among local authority employees:

There has been... a lot of tension between the various user groups in the park, i.e. the grassroots community groups that are using the space and doing a lot of the 
growing... versus the council staff and the pressures they're under with cuts. And people doing jobs that they didn't originally have, being put into positions that they feel probably very overwhelmed by.

(RFW growing coordinator 1)

In an environment where staff are overstretched and periodically asked to compete for their positions, it should perhaps come as little surprise that affected individuals can seem reluctant to welcome external initiatives such as RFW that appeared to be perceived as superfluous interventions requiring time and effort to organise. In the early stages of the project, the RFW growing coordinator was informed that a member of park staff would coordinate the various growing groups, as a level of collaboration was deemed necessary in order to support the needs of the groups and to make best use of the space. In reality, observations suggested that there was little overarching management of growing space from within the park for individual groups, possibly due to a lack of management capacity. This effectively made it impossible for the various growing groups to work as a collective, potentially diminishing the efforts of the individuals who volunteered their time.

The lack of coordination also led to confusion among volunteers regarding allocated growing areas and responsibilities. One RFW volunteer felt that there were "too many growing groups" working on different projects in a shared space and that cultivating such a large area frequented by numerous people led to doubts over which areas were being used by which organisations. He recalled an occasion when plants were wasted due to a misunderstanding over the allocation of space in the park:

\footnotetext{
We took one of the patches and we put a load of peas in, and then the next week when we come in on the Wednesday... it had all been dug out and someone had put potatoes in with the peas... So, it was kind of like, last Wednesday was a waste of time coming in.
}

(Dean, RFW volunteer)

The coordination shortcomings that this example implies resulted in participants struggling to understand their role and rather than building confidence in their growing skills, the uncertainty left participants feeling unsure of whether their actions were a help or a hindrance. Another volunteer viewed the diversity and multitude of growing groups as a potentially positive feature 
of the park, acknowledging that the situation could be improved if the various projects were able to work together rather than duplicating work and wasting produce (Dylan, RFW volunteer). Dean also noted that the competition between groups was curious given that the growers all had a common goal, but questioned RFW's ability to integrate with other groups due to the nature of its funding:

There's so much division in here because everyone is trying to outdo everyone... and they're all just focused on their own things instead of thinking, "We're all growing veggies"... You need a bit of give and take between them. But then Real Food is Lottery based so it has got to have its shield around it.

(Dean, RFW volunteer)

This comment raises questions regarding the mechanisms by which fixed-term externally funded projects can fit into existing foodscapes and the ways in which they are viewed by other organisations. This is of particular interest during a time of austerity where volunteer groups are assuming higher levels of responsibility for the management of public spaces and competition for resources and funding between groups is high (Rosol, 2012).

During observations at the park, there was clearly tension between the existing growing community, the park staff and RFW volunteers, with the project manager noting that following the winter of the second year of the project, the staff at the park had "regrouped and blocked [RFW] out again" (RFW project manager). Subsequently, RFW experienced difficulties accessing space within the park for growing and storing plants. According to the RFW growing coordinator, the act of producing a large crop of vegetables caused concern among other growing groups:

Last year... that glasshouse was absolutely full... While the other glasshouses didn't have anything in. I would've happily spread out into another glasshouse, but that wasn't an option... that affects the relationships in the park. [The other groups think], “Oh you're doing all that and we've hardly got anything. It makes us look bad".

(RFW coordinator 2) 
This was a source of frustration for the growing coordinator, who stated, "It shouldn't be like that. It's just about using the available space... It's not in competition with each other, we're doing this together!" (RFW growing coordinator 2). RFW eventually decided that attempts towards collaboration at the park were futile:

\begin{abstract}
All I know is that there are only two [paid members of park staff]; it's a very big park... That is totally infeasible... I'm not willing to do this fitting in with people who haven't got the time for the partnership work... It's nonsense, that's not what my role's about.
\end{abstract}

(RFW growing coordinator 2)

Conflicts made the experience more stressful for RFW volunteers, who felt that they were constantly at risk of planting vegetables in the wrong patch or using another group's plant pots. At this time, the RFW volunteers were sharing the use of one of the glasshouses in the horticultural centre with another growing group, with a clear divide between the two sides of the room. One volunteer, expressed frustration over the division within the park, seeing the opposition as unnecessary. She suggested that it was the responsibility of the park management to ensure that all the various groups treated the park as a shared space, stating, "I like a joke with everyone, so I find it quite hard to even comprehend that adults are like this" (Amy, RFW volunteer).

Similar behaviour has previously been associated with community growing projects, with Schmelzkopf (1995, p. 376) recalling "not-uncommon" occurrences of "power struggles and backbiting" among community gardeners in New York City, describing this simply as "garden politics". The somewhat hostile environment created within the park perhaps reflects the uncertainty felt by voluntary groups given the existing financial climate where funding is difficult to secure, leaving organisations to compete against one another in order to survive. The need to compete can prove debilitating when it results in groups with similar goals, such as providing vegetables for the local community, feeling unable to cooperate with one another and consequently duplicating work or nullifying progress. Difficulties in collaboration were experienced elsewhere within the project, with the following section reflecting on some early problems RFW encountered in partnership work with external organisations at a more structural level. 
Inter-organisational collaboration at a partnership level

The obstacles to collaboration were not confined to grassroots-level activities at the project's growing sites, they also affected the initiative on a structural level between partnering organisations. One of the strengths of the funding bid was the involvement of two large housing associations, which later merged, acting as the project's lead partner. The housing association had the responsibility of managing the project's budget with the remaining partners acting as steering groups, working in an advisory capacity. A theme that emerged strongly through interviews with staff members and bid authors related to project partnerships and the ways in which these had been arranged, maintained or in some cases, lost or terminated.

Drawing on management literature, it is clear that coordinating inter-organisational collaboration is a reliably difficult task requiring active management in order to generate successful partnerships (Huxham \& Vangen, 2005). Huxham and Vangen (1996, p. 6) note that "many collaborative arrangements which begin with the best of intentions and goodwill nevertheless turn out to be frustrating affairs and it is not uncommon for them to dwindle away into non-existence." Indeed, RFW originally had a diversity of partners with expertise in a number of areas from health and mental wellbeing to communications and innovative design; however, several organisations withdrew from the project in its early stages. This had the effect of narrowing the project's reach and potentially the level of impact the initiative was able to have on the resident population.

An author of the RFW funding bid observed that while the partners were initially positive about the idea of a food-based intervention in Wythenshawe, the bidding process did not allow sufficient time to establish the appropriate actors within organisations to ensure their continued commitment throughout the project implementation phase:

\begin{abstract}
[A] challenge... was the level of buy-in at this stage from the partners... because of the speed that the bid had to be submitted. Although all the Wythenshawe partners in particular were very committed to the big idea... the people round the table in the first phases... might not have been the right people within that organisation to grasp what was needed.
\end{abstract}

(Bid author 1) 
An interesting aspect of RFW was that the manager and coordinators played no part in the design or submission of the funding application. During the early stages of the project delivery, another author of the bid felt that there was a lack of understanding among the partners and project coordinators regarding the vision and aims of the project. The project's initial growing coordinator attributed some of the tensions between project partners to "politics, people's agendas and the understanding of the bid" and regretted the lack of collaboration concerning a common vision for the project among the partnering organisations. She suggested that planning "strategic visioning" would be a "valuable activity into the future", highlighting the importance of partnering organisations moving "in the same direction" and having "similar perspectives" on what the project was attempting to achieve (RFW growing coordinator 1).

As Hardy and Phillips (1998) have observed, given that partnering organisations often have differing understandings of their role and represent contrasting priorities and values, it seems reasonable to question whether collaboration is always a productive endeavour. The RFW project manager acknowledged that managing partnerships and ensuring continued commitment was a considerable task:

Initially the partners came along, in the first year we got good attendance at meetings [whereas now]... I think they think "well actually, they're doing it, we don't really need to go to the steering meeting"... And lots of the partners have changed... Some have fallen by the wayside so it is frustrating that they... don't get involved.

(RFW project manager)

The departure of a number of the original partners appears to be linked to the distribution and control of the budget. The project manager noted that when partners attended meetings, they often began by asking “"“what's in it for me?" [and] "how much money can you give me?", "we want a slice of the cake"" (RFW project manager). If UA projects rely on charitable or voluntary involvement, it may be difficult for organisations to commit to their roles, particularly given the likelihood of changing priorities and structures. This leads to the question of how to ensure commitment from partners that cannot sustain themselves without a financial return. A representative from the housing association suspected that the work of partnering organisations "has to have budget attached", adding that: 


\begin{abstract}
The problem comes when the whole budget is held with one team. The great advantage [is that the coordinators]... get a really good amount of control over what they're allowed to do... the downside... is that that doesn't lend itself to partnership working... If you've got money flowing between the partners, then they have permission... to get involved and stay involved.
\end{abstract}

(Housing association representative)

The decision for the RFW lead partner to maintain control of the budget was in some ways a deviation from the project design. As one author of the bid observed, RFW "needed a core of staff, but the idea was never that those staff would be the delivery agents... It would be the different organisations who were leading on it" (Bid author 2). She believed that a more even distribution of budget and responsibility would have augmented the scope and effectiveness of the project.

Huxham and Vangen (1996) observed that collaborations with an imbalance in the resources available or in the sizes of organisations involved may lead to smaller organisations feeling "very vulnerable", making tensions more likely to arise in collaborations where only one organisation has control of the financial resources (Huxham \& Vangen, 1996, p. 14). This suggests that holding the project's entire budget within one central organisation can lead to a dynamic whereby the partnering organisations do not feel that they have sufficient control over relevant aspects of the project and lack the autonomy to use their particular expertise to its full potential. Findings suggest that by relinquishing responsibility for some project activities and by decentralising control of relevant portions of the project budget, RFW may have been better placed to strengthen partnerships and collaboration throughout the project delivery stage.

\title{
Conclusion
}

In recent years, a growing number of authors, notably those concerned with food justice, have adopted a critical lens to analyse some of the more problematic attributes of UA (Rosol, 2012; Tornaghi, 2014). This paper has raised the issue of collaboration in UA projects, beginning by acknowledging the challenging funding environment within local authorities and between charitable organisations that can lead to groups with similar goals competing with one another at the expense of cooperation. Conflict was evident during observations and interviews at Wythenshawe Park, where a number of growing groups competed for space and resources, and were unreceptive to new groups using the area as a base for operations. This behaviour reflects 
the need for organisational self-preservation within a competitive funding environment, but results in groups with similar goals and often complementary ideologies working against one another rather than in cooperation. As a result, RFW found the park to be a challenging environment in which to integrate.

It has been observed that withdrawal of state support and the institutionalisation of volunteering can lead to competition between third sector organisations, frequently at the expense of collaboration, which could have a detrimental impact on their ability to sustain or upscale potentially beneficial activities (Rosol, 2012). In the case of RFW, these conflicts served to provide distractions and potentially compromised the levels of progress achieved. The experience of the growing groups based in Wythenshawe Park would suggest that this inhibited groups' ability to work together in order to become more than the sum of their parts. While Tornaghi (2017, p. 783) calls for a "confluence of the cracks", evidence from Wythenshawe suggests that an environment depleted by nearly a decade of austerity measures, has led to the isolation rather than the convergence of individual cracks.

The expanding critical literature on UA has begun to acknowledge the practice's tendency to further the entrenchment of neoliberalism by inadvertently providing alternatives to services traditionally offered by the state. This shift describes a process of retraction of central government, and an attempt by civil society to fill gaps in provision. Rosol (2012) views the rise of volunteering as an important part of this process, aspects of which were visible in Wythenshawe. The voluntary and frequently piecemeal nature of many urban growing projects invites questions regarding UA's ability to upscale and address food justice issues effectively. While we would not argue in favour of the further institutionalisation of unpaid labour, this aspect of UA projects is at the heart of an instability that appears to exacerbate inefficiencies of supply and does very little to combat social injustice. In the case of the urban farm in Wythenshawe, the irregular supply of food generated from an unstable, unpaid workforce was not sufficient to provide the farm outlet with reliable levels of stock. A limited or unpredictable supply was accompanied by an uncertain demand, occasionally resulting in a proportion of the harvests being fed to livestock or going to waste.

On a broader scale, a number of the partnerships formed in the early stages of the RFW project development proved difficult to maintain. It appears that these difficulties were primarily due to a lack of financial distribution to partnering organisations and the concentration of control of budget and project activities within the initiative's lead partner. While this approach afforded 
the project coordinators a greater level of autonomy over the project implementation, it may have limited the scope and reach of the initiative.

We do not dispute the numerous beneficial aspects of UA, however its ability to assist in the reconfiguration of a more just and sustainable food system and to make significant changes to the ways in which urban dwellers conceive of, access and value their food is still unclear (Hardman, St. Clair, et al., 2018). We agree with Tornaghi (2017) that the production of food as a specific and deliberate outcome of UA initiatives, particularly in the UK, is still an area that deserves further attention (Hardman, St. Clair, et al., 2018). Given recent interest in the potential for the upscaling of UA activities, this is an important consideration for future investors. In light of the findings detailed in this paper, we call for researchers embedded in UA projects, particularly in the UK, to offer examples of productive collaborations between local organisations devoted to food justice and UA. We also perceive a continued need for researchers and practitioners to differentiate between varying forms of UA projects such as community gardens and urban farms and to highlight not only where initiatives succeed, but also where they encounter obstacles and, if possible, how barriers are overcome.

It is important to note, as Kato et al. (2014) also have, the type of research conducted here is limited to a particular location and timeframe and covers only a snapshot of the project's development. We hope that the observations described here will be informative for other UA projects embarking on a comparable journey. We would also like to acknowledge and celebrate the existence of a great number of beneficial attributes of community growing and UA projects. In this spirit, this paper has sought to draw attention to the constraints placed upon the ability to upscale, expand and progress these positive impacts due to a political landscape that appears to foster competition at the expense of collaboration. 


\section{References}

Alaimo, K., Beavers, A. W., Crawford, C., Snyder, E. H., \& Litt, J. S. (2016). Amplifying Health Through Community Gardens: A Framework for Advancing Multicomponent, Behaviorally Based Neighborhood Interventions. Current Environmental Health Reports, 3(3), 302-312. doi:10.1007/s40572-016-0105-0

Alexander, J., Nank, R., \& Stivers, C. (1999). Implications of Welfare Reform: Do Nonprofit Survival Strategies Threaten Civil Society? Nonprofit and Voluntary Sector Quarterly, 28(4), 452-475. doi:10.1177/0899764099284005

Alkon, A. H., \& Agyeman, J. (2011). Cultivating food justice: Race, class, and sustainability: MIT Press.

Armstrong, D. (2000). A survey of community gardens in upstate New York: Implications for health promotion and community development. Health \& Place, 6(4), 319-327.

Baker, L. E. (2004). Tending Cultural Landscapes and Food Citizenship in Toronto's Community Gardens. Geographical Review, 94(3), 305-325.

Bell, S., \& Cerulli, C. (2012). Emerging community food production and pathways for urban landscape transitions. Emergence: Complexity and Organization, 14(1), 31.

Bellows, A. C., Brown, K., \& Smit, J. (2003). Health benefits of urban agriculture. Community Food, 1-8.

Birks, M., \& Mills, J. (2015). Grounded theory: A practical guide: Sage.

Cassidy, C. (2018). [Freedom of Information Request].

Charmaz, K. (2006). Constructing grounded theory: A practical guide through qualitative research. SagePublications Ltd, London.

Church, A., Mitchell, R., Ravenscroft, N., \& Stapleton, L. (2015). 'Growing your own': A multi-level modelling approach to understanding personal food growing trends and motivations in Europe. Ecological Economics, 110, 71-80.

Colasanti, K. J. A., Hamm, M. W., \& Litjens, C. M. (2012). The City as an "Agricultural Powerhouse"? Perspectives on Expanding Urban Agriculture from Detroit, Michigan. Urban Geography, 33(3), 348-369. doi:10.2747/0272-3638.33.3.348

Corcoran, M. P., \& Kettle, P. C. (2015). Urban agriculture, civil interfaces and moving beyond difference: the experiences of plot holders in Dublin and Belfast. Local Environment, 20(10), 1215-1230. doi:10.1080/13549839.2015.1038228 
Crossan, J., Cumbers, A., McMaster, R., \& Shaw, D. (2016). Contesting neoliberal urbanism in Glasgow's community gardens: The practice of DIY citizenship. Antipode, 48(4), 937-955.

Cumbers, A., Shaw, D., Crossan, J., \& McMaster, R. (2018). The Work of Community Gardens: Reclaiming Place for Community in the City. Work, Employment and Society, 32(1), 133-149. doi:10.1177/0950017017695042

Draus, P. J., Roddy, J., \& McDuffie, A. (2014). 'We don't have no neighbourhood': Advanced marginality and urban agriculture in Detroit. Urban Studies, 51(12), 25232538. doi:10.1177/0042098013506044

European Federation of City Farms. (n.d.). European Federation of City Farms: Mission. Retrieved from https://cityfarms.org/mission

Ferris, J., Norman, C., \& Sempik, J. (2001). People, Land and Sustainability: Community Gardens and the Social Dimension of Sustainable Development. Social Policy \& Administration, 35(5), 559-568. doi:doi:10.1111/1467-9515.t01-1-00253

Franklin, A., Kovách, I., \& Csurgó, B. (2016). Governing Social Innovation: Exploring the Role of 'Discretionary Practice' in the Negotiation of Shared Spaces of Community Food Growing. Sociologia Ruralis, 57(4), 439-458. doi:doi:10.1111/soru.12126

Fyfe, N. R., \& Milligan, C. (2003). Out of the shadows: exploring contemporary geographies of voluntarism. Progress in Human Geography, 27(4), 397-413.

Ghose, R., \& Pettygrove, M. (2014). Urban community gardens as spaces of citizenship. Antipode, 46(4), 1092-1112.

Gold, R. L. (1958). Roles in sociological field observations. Social forces, 217-223.

Hardman, M., Chipungu, L., Magidimisha, H., Larkham, P. J., Scott, A. J., \& Armitage, R. P. (2018). Guerrilla gardening and green activism: Rethinking the informal urban growing movement. Landscape and Urban Planning, 170, 6-14. doi:https://doi.org/10.1016/j.landurbplan.2017.08.015

Hardman, M., \& Larkham, P. J. (2014). Informal Urban Agriculture: The secret lives of guerilla gardeners. London: Springer.

Hardman, M., St. Clair, R., Adams, D., Armitage, R. P., Barry, V., Larkham, P. J., \& Sherriff, G. A. (2018). Urban agriculture: evaluating informal and formal practices. North West Geographer, 18(1), 1-10.

Hardy, C., \& Phillips, N. (1998). Strategies of engagement: Lessons from the critical examination of collaboration and conflict in an interorganizational domain. Organization science, 9(2), 217-230. 
Hastings, A., Bailey, N., Bramley, G., Gannon, M., \& Watkins, D. (2015). The cost of cuts: the impact on local government and poorer communities. Retrieved from https://www.jrf.org.uk/sites/default/files/jrf/migrated/files/Summary-Final.pdf Hindle, P. (2018). [Freedom of Information Request]. Holloway, J. (2010). Crack capitalism: Pluto Press (UK).

Horst, M., McClintock, N., \& Hoey, L. (2017). The Intersection of Planning, Urban Agriculture, and Food Justice: A Review of the Literature. Journal of the American Planning Association, 83(3), 277-295. doi:10.1080/01944363.2017.1322914

Huxham, C., \& Vangen, S. (1996). Working together: Key themes in the management of relationships between public and non-profit organizations. International Journal of Public Sector Management, 9(7), 5-17. doi:doi:10.1108/09513559610153863

Huxham, C., \& Vangen, S. (2005). Managing to collaborate : the theory and practice of collaborative advantage. London: Routledge.

Kato, Y., Passidomo, C., \& Harvey, D. (2014). Political Gardening in a Post-disaster City: Lessons from New Orleans. Urban Studies, 51(9), 1833-1849. doi:10.1177/0042098013504143

Kneafsey, M., Owen, L., Bos, E., Broughton, K., \& Lennartsson, M. (2017). Capacity building for food justice in England: the contribution of charity-led community food initiatives. Local Environment, 22(5), 621-634.

MacKinnon, D. (2000). Managerialism, governmentality and the state: a neo-Foucauldian approach to local economic governance. Political geography, 19(3), 293-314.

MCC. (2017). Manchester's Park Strategy 2017-2027: Ten-Year Action Plan. Manchester. McClintock, N. (2014). Radical, reformist, and garden-variety neoliberal: coming to terms with urban agriculture's contradictions. Local Environment, 19(2), 147-171.

McClintock, N., \& Simpson, M. (2018). Stacking functions: identifying motivational frames guiding urban agriculture organizations and businesses in the United States and Canada. Agriculture and Human Values, 35(1), 19-39.

Milbourne, P. (2012). Everyday (in) justices and ordinary environmentalisms: community gardening in disadvantaged urban neighbourhoods. Local Environment, 17(9), 943957.

Milligan, C. (2000). 'Breaking out of the asylum': developments in the geography of mental ill-health — the influence of the informal sector. Health \& Place, 6(3), 189-200.

Mougeot, L. J. (2010). Agropolis:" The Social, Political and Environmental Dimensions of Urban Agriculture": Routledge. 
Okvat, H. A., \& Zautra, A. J. (2011). Community gardening: A parsimonious path to individual, community, and environmental resilience. American journal of community psychology, 47(3-4), 374-387.

Open Data Communities. (2015). Indices of Deprivation 2015 Explorer. Retrieved from http://dclgapps.communities.gov.uk/imd/idmap.html

Pudup, M. B. (2008). It takes a garden: Cultivating citizen-subjects in organized garden projects. Geoforum, 39(3), 1228-1240.

Rosol, M. (2012). Community volunteering as neoliberal strategy? Green space production in Berlin. Antipode, 44(1), 239-257.

Schmelzkopf, K. (1995). Urban Community Gardens as Contested Space. Geographical Review, 85(3), 364-381. doi:10.2307/215279

Smit, J., \& Nasr, J. (1992). Urban agriculture for sustainable cities: using wastes and idle land and water bodies as resources. Environment and urbanization, 4(2), 141-152.

Spradley, J. P. (2016). Participant observation: Waveland Press.

St. Clair, R., Hardman, M., Armitage, R. P., \& Sherriff, G. (2017). The trouble with temporary: Impacts and pitfalls of a meanwhile community garden in Wythenshawe, South Manchester. Renewable Agriculture and Food Systems, 1-10.

Tornaghi, C. (2014). Critical geography of urban agriculture. Progress in Human Geography, $38(4), 551-567$.

Tornaghi, C. (2017). Urban Agriculture in the Food-Disabling City: (Re)defining Urban Food Justice, Reimagining a Politics of Empowerment. Antipode, 49(3), 781-801. doi:10.1111/anti.12291

Wolfinger, N. H. (2002). On writing fieldnotes: collection strategies and background expectancies. Qualitative research, 2(1), 85-93. 